\title{
Life Kinetiğin Performans Sporcuları Üzerine Etkileri
}

\author{
İmdat YARIM@*1, Ebru ÇETIN®1, Özlem ORHAN@1 \\ ${ }^{1}$ Gazi Üniversitesi Spor Bilimleri Fakültesi
}

Derleme
Gönderi Tarihi: 25.06.2019
Kabul Tarihi: 31.10.2019

DOI: $10.25307 /$ jssr.581943

Online Yayın Tarihi: 31.12.2019

\section{$\ddot{O} \mathbf{z}$}

Sportif performans açısından iyi planlanmış bilimsel temellere dayanan antrenman içeriklerinin önemi bilinmektedir. Antrenman içeriklerinde life kinetik egzersizlerinin (LK) performansa etkileri ve beceri öğrenme hızı ile koordinatif yeteneklerin gelişimine olan katkısı son yıllarda dikkat çekmektedir. Yapılan çalışmalar, life kinetiğin öğrenme sürecini hızlandırarak, merkezi sinir sisteminde yeni yapılanmalar oluşturduğu, konsantrasyonu ve performansı iyileştiren bir egzersiz sistemi içerdiğinden bahsetmektedir. Life kinetiğin farklı etkileri ve uygulanan değișken içerikleri, sporcularda branşlarına özgü görsel ve kinestetik süreçleri birbirine bağlamak yoluyla performansı etkileyebilmektedir. Life kinetik farklı hareket modelleri, görsel görevler ve bilişsel elementlerden kombine edilen eş zamanlı egzersizler ile çalışılan bir metot olduğu bilinmektedir. Sözü geçen bu egzersizler sporcuları sürekli kendisine bağlamak ve motive etmek için her zaman eğlencelidirler. Life kinetik tüm bunları kişilerin yeteneğine göre, değişen zorluk seviyesindeki egzersizlerin yardımıyla başarır. Sportif branşlarda LK egzersizlerinin kullanımı sıklıkla öğrenme, teknik ve taktik gelişime de katkı oluşturup oluşturulamayacağ üzerinde merak uyandırmaktadır. İyi bir performans için kas kuvvetinin yanı sıra, maksimum hareket hızı ve nöromüsküler aktivasyon da önemlidir. Life kinetik ile sporcular iyi antrene edilmiş koordinatif yeteneklere sahip olabilir ve dolayısıyla da performanslarına katkılar sağlanabilir. Bu çalışma farklı branşlarda performans sporcularının LK kullanımlarını ve etkilerinin özetlenmesi amacıyla yapılmıștır.

Anahtar kelimeler: Life kinetik, performans, spor branşları.

\section{Effects of Life Kinetics on Performance Athletes}

\begin{abstract}
The importance of training contents based on well-planned scientific foundations is known for a good sporting performance. The effects of life kinetics (LK) on performance, contribution of speed of learning skills and development of coordinative abilities have attracted attention studies indicate that life kinetics accelerates the learning process, creating new neural structures, and an exercise system that improves concentration and performance. Different effects of life kinetics and the variable contents applied can affect performance by linking visual and kinesthetic processes specific to their branches in athletes. Life kinetic is known to be a method studied with different motion models, visual tasks and simultaneous exercises combined from cognitive elements. These exercises are always fun to connect and motivate athletes. Life kinetic accomplishes all of this with the help of difficulty-level exercises that vary according to the ability of the individual. The use of LK exercise in sport branches often raises curiosity as to whether learning can contribute to technical and tactical development. In addition to muscle strength, maximum movement speed and neuromuscular activation are also important for good performance. With LK, athletes can have well-coordinated coordinated skills and thus contribute to their performance. The aim of this study is to summarize the effects of the LK usage and performance in different sports branches.

Keywords: Life kinetics, performance, sport branch.
\end{abstract}

"Sorumlu Yazar: İmdat YARIM, Gazi Üniversitesi Spor Bilimleri Fakültesi, E-posta: imdat@gazi.edu.tr, Tel: 05322650232 


\section{GíRiş}

Almanya'da geliştirilen Life Kinetik (LK) egzersizleri, günümüzde dünyanın birçok ülkesinde uygulanan nöronsal öğrenme sürecini canlandırarak, yeni beyin ağlarını yapılandırıp sinirsel semptomları azaltırken, konsantrasyonu ve görsel sistemin performansını iyileştiren bir eğitim programı olarak kullanılmaktadır (Lutz, 2011). Life kinetik tüm bunları kişilerin yeteneğine göre değişen zorluk seviyesindeki egzersizlerin yardımıyla başarmaktadır. Kişilerin yeteneği geliştikçe LK egzersizlerinin beyni daha fazla geliştirmek için giderek zorlaştırılması önerilmektedir. $\mathrm{Bu}$ egzersiz modelinin kullanımı geniş çaplı bir alana yayılmaktadır. Çocuklarda, yetişkinlerde, yaşlılarda ve hatta sporcularda da kullanılabilmektedir. Aralarında Olimpiyat ve Dünya şampiyonlarının da bulunduğu elit sporcular son yıllarda LK eğitim programlarını antrenmanlarının içerisinde giderek artan miktarlarda kullanmaya başlamışlardır. Bununla birlikte LK ile ilgili olarak bilimsel çalışmalarında doğru orantılı olarak arttı̆̆ı söylenebilir. Yapılan bilimsel çalışmalar haftada sadece bir saat bile LK ile konsantre olma yeteneğinin arttı̆̆ını, fiziksel ve motorik özelliklerde de gelişmeler olduğunu göstermiştir (Lutz, 2014). Life kinetik programlarını geliştiren ve ilk egzersiz kitabının da yazarı olan Host Lutz (2002), kitabında life kinetiğin geniş çapta koordine edilmiş egzersiz programı yolu ile hem fiziksel hem de mental sağlık açısından önemli olduğuna ısrarla değinmiştir.

Günümüzde sportif branşlar için en iyi performans yalnızca titizlikle planlanan, uygulanan ve kontrol edilen temelleri, metodu ve teoriği bilimsel geçerliliği olan bilgiler üzerine dayandırılan bir antrenman sistemi vasıtasıyla elde edildiği bilinmektedir. Üst düzey bir performans seviyesi teknik, taktik, fiziksel kondisyon, psikolojik kalite ve koordinasyon bileşenlerinin tümünü antrene ederek ve çalışarak kazanılır (Pietsch, Böttcher ve Jansen, 2017). Becerinin öğrenme hızı ve istikrarı, çeşitli koordinatif yeteneklerin seviyesine doğrudan bağlıdır. Yeteneklerin, teknik ve taktik becerilerin en üst düzeyde kullanımı için koordineli olmasına ihtiyaç vardır (Jain, Bansal, Kumar ve Singh, 2015). Spor branşlarında iyi performansı motor koordinatif yetilerin uyumu belirler (Faigenbaum vd., 2013). Zihinsel rotasyonun altında yatan süreçler ile ilgili olarak Funk, Brugger ve Wilkening (2014), akılda dönen figürlerin sadece zihinsel bir çaba olmadığını, bunun bireyin fiziksel hareketleri ile bağlantılı olduğuna inanmaktadır. Bu anlayış zihinsel süreçlerin motor işlemlere aracılık ettiğini göstermektedir. Performans sporlarında hareketi çabuk kavrayıp, hızlı karar alabilen ve bu yeteneklerini de performanslarına yansıtanlar iyi bir sporcuya dönüşebilirler. Yapılan araştırmalarda, farklı branşlardaki ve takımlardaki elit sporcular LK'in etkilerini uygulamalar sonrası hissettiklerini ve koordinatif yetileri üzerinde olumlu katkıları olduğunu bildirmişlerdir (Peker ve Taşkın, 2016). Literatür bilgilerine bakıldığında bu egzersiz tipinin yaygın olarak futbolcular üzerinde kullanıldığını hatta pek çok profesyonel futbol takımının bu antrenmanlar için bünyelerinde özel bir kadro oluşturduğu da bilinmektedir (Vural, 2016). Life Kinetik egzersizlerinin kullanımı da giderek yaygınlaşırken, yeterince bilimsel araştırma ve kanıta dayalı çalışmaların azlığıda dikkat çekmektedir. Farklı etkileri ve gelişimleri beraberinde getiren bu uygulama şekline dikkat çekmek, kullanımını artırmak ve bilimsel kanıtlar sunulmasının büyük ihtiyaç olduğu düşünülmektedir.

$\mathrm{Bu}$ çalışmanın amacı, LK'in sporcularda performans parametreleri ve antrenmanlardaki gelişimleri üzerine yapılan çalışmaların özetini içeren bir derleme yapmaktır. Daha sonra ise 
spor dallarında sportif performansın arttırılması amacıyla bir araç olarak LK' in etkisi üzerine dikkat çekmektir.

\section{Performans Sporcularında Life Kinetik Uygulamaları ve İçerikleri}

Life Kinetik, beyin hücreleri arasında yeni bağlantılar oluşturan, görsel görevleri, hareketleri ve bilişsel görevleri birleştiren egzersizler kullanarak, fiziksel aktivite yoluyla beyin eğitimi sağlayan bir sistem içermektedir. Egzersizler konsantrasyon, problem çözme becerileri, refleksler, denge, koordinasyon ve aynı zamanda performans sporcuları için stres ile başa çıkma yeteneği üzerinedir. Life kinetik uygulamaları 3 temel üzerine dayandırılmaktadır. Bunlardan ilki “esnek vücut kontrolü” olarak adlandırılır. Bu uygulamalarda diş dünyadan gelen uyaranlara karşı hazır olma ve uygun şekilde cevap verme becerileri hedeflenir. İkinci olarak vücut koordinasyonu için ihtiyaç duyulan "görsel sistem" dir. Üçüncü başlık "bilişsel beceriler" i kapsamaktadır. Bu süreçte ise mümkün olduğunca fazla bilgiyi olabildiğince hızla işlemek en temel esastır (FIFA, 2019; Lutz, 2014) Esnek vücut kontrolü kapsamında beynin ve vücudun daha esnek bir şekilde teknikleri uygulaması mümkün olur. Her sporcu antrenmanlarında müsabaka durumundaki tüm şartları deneyimlemeyi hedefler. Bu durum da müsabaka sırasında daha önceden öğrenilmiş hareketlerin daha iyi bir performansla ortaya konulmasını sağlar. Esnek vücut kontrolü hareketleri içeriğinde iki düzensiz hareket arasında değişiklik yapmak (hareket değişikliği), İki hareketi birleştirmek (hareket zinciri) ve düzenli ve düzensiz hareketleri bağlamak (hareket akışı) tarzında egzersizler uygulanır (Lutz, 2010). Görsel sistem, çevresel faktörler, hareketin uygulandığı zeminin özellikleri, mesafe ve kullanılan araç gerece adaptasyon ile ilgili durumlarda ön plana çıkmaktadır. Bu durumlarda veri sağlamasının yanında vücut bileşenlerinin işlevleri, aralarındaki ilişki ve gereken hareket miktarı hakkında da bilgi sağlamaktadır. Hareket hızı ve zorluk derecesi arttığı zaman görsel sistem bileşenlerinin işlevlerinin önemi de artacaktır (Lutz, 2010). LK'in öğrenme üzerinde en etkili aracı bilişsel gelişim bileşenidir. Bu temel üzerinde uygulanan LK egzersizleri bilişsel yetenekleri geliştirmeyi hedefler (Chib, 2000).

Life kinetik ile bilişsel yetenekler geliştirilmekte ve performans için önemli kriterlerden olan alg1, problem çözme, dikkat ve muhakeme gibi özelliklerin gelişimi sağlanmaktadır. Özellikle LK egzersizlerinin derece derece zorlaşması ve hareketlerin sürekli olarak değiştirilmesi bu eğitim sürecinin daha etkili olmasını destekler. LK uygulamaları, sporcularda durumları daha hızlı analiz etmeyi ve buna göre tepki vermeyi sağlar. Uygulamalar bireysel, eşli veya grup içerisinde yapılabilmektedir. Sporcular program içerisinde sürekli değişen, zorlaşan veya giderek kolaylaşan hareketlerle alışık olmadıkları durumlara adaptasyon sağlamaya çalışır. Egzersizler iki farklı şekilde zorlaştırılabilir. İlk olarak zihinsel görev dediğimiz bilişsel görev zorlaştırılarak daha karmaşık şekle dönüştürülebilir. İkincisi ise egzersizin uygulanış biçimi daha zor bir hale getirilebilir. Bu şekilde, otomatik cevaplama önlenir ve yeni uyaranlar üretilir. Mükemmellik için gayret göstermeye ve egzersizleri tamamen ustalaşıncaya kadar tekrarlamaya alışık olan sporcular için, bu yaklaşım ilk önce büyük bir düşünce değişikliği gerektirir. $\mathrm{Bu}$ düşünce değişikliğinin felsefesini kavrayan sporcular bu durumdan zevk alıyorlar ve eğleniyorlar. Sporcular hızla bu yeni duruma adapte oluyorlar ve performansları kısa zamanda artıyor. Bu felsefe değişikliği mükemmeliyetçiliği ortadan kaldırıyor ve hatta mükemmel düzeyde yapılmayan hareketlerin de farklı avantajlar sağladığını ortaya koyuyor. Çünkü beyin sürekli çalışıyor ve yeni şartlara uyum sağlayıcı farklı yöntemler keşfediyor (Lutz, 2014; FIFA, 2019). 
Life kinetik uygulamaları sırasında farklı koordinatif yetenekleri geliştirici, egzersizleri eğlenceli ve daha yapılabilir kılan pek çok araç-gereç kullanılmaktadır. Bu materyallere örnek olarak farklı boy, renk ve ağırlıktaki toplar, renkli çember, kurdela, ip, kuka ve göz bantları verilebilir (Resim 1,2). Ayrıca uygulanan spor branşına (raket sporlan, toplu sporlar, bireysel sporlar) göre kullanılacak malzemeler çeşitlilik göstermektedir.

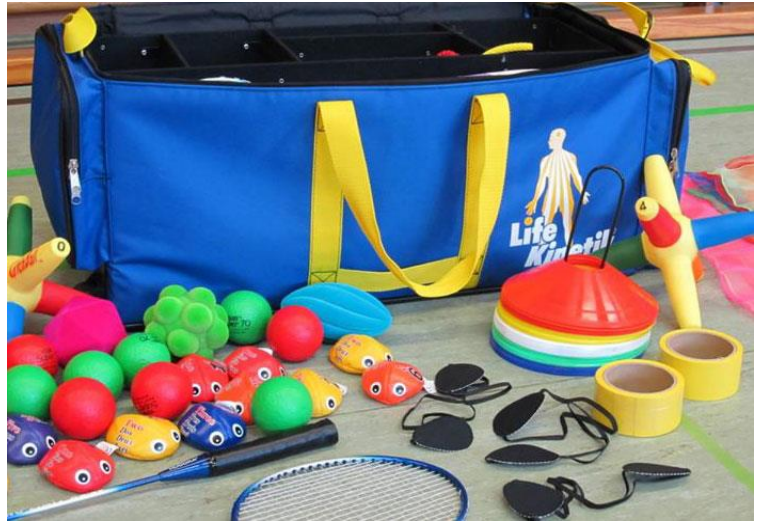

Resim 1: LK malzemeleri* *https://www.stadtzeitung.de/augsburg-nordwest/sport/life-kinetik-workshop-+-schnupperstunde-d36439.html

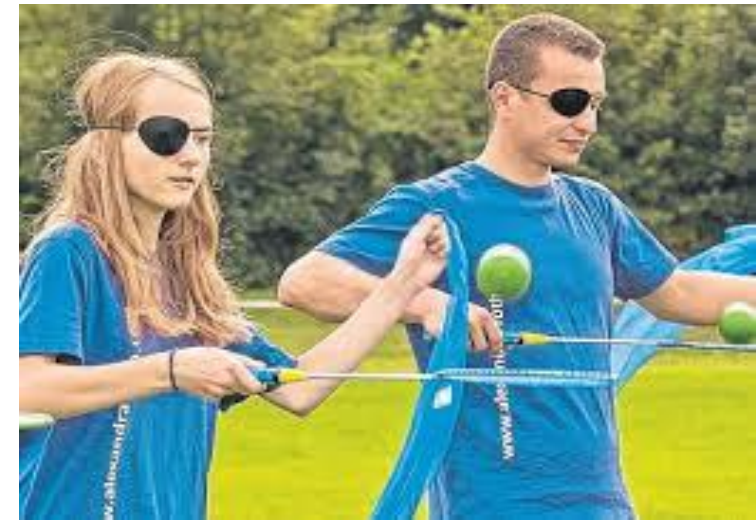

Resim 2: LK uygulama biçiminden bir örnek ${ }^{*}$

\section{Performans Sporcularında Life Kinetiğin Etkilerinin Araştırıldığı Çalışmalar}

Performans sporcularında son yıllarda yapılan çalışmalar incelenmiş ve LK'in etkileri özetlenmeye çalışılmıştır. Araştırmadan elde edilen bilgiler doğrultusunda life kinetik nöronal öğrenme sürecini canlandırmaktadır. Öğrenme sinaptik plastisite yolu ile gerçekleşir (Nelson, 2000). Bu süreçte beyinde gerçekleşen nöroplastisitenin özellikle beynin görme, işitme ve motor beceriler ile ilgili alanlarında olduğu saptanmıştır (Hyde vd., 2009). Egzersiz, beyin plastisitesini destekleyen ve sürdüren moleküler ve hücresel basamakları aktive eder. Bunun yanı sira uygulanması basit ve yaygındır (Cotman ve Berchtold, 2002). LK egzersizleri de bu kapsamda kullanılarak yeni beyin ağları yapılandırmakta, sinirsel semptomları azaltmakta ve konsantrasyonu artırarak performansını iyileştirebilmektedir. Penka, askeri üniversite öğrencileri üzerinde yaptığı, çalışmasında, LK'in denge, göz-el ve göz-ayak koordinasyonu üzerinde etkili olduğunu tespit etmiş̧ir (Life Kinetik, 2019). Yapılan bir başka çalışmada, life kinetik eğitiminin fonksiyonel beyin bağlanabilirliği üzerindeki etkisini araştırmışlardır. 4 haftalık bir eğitim sürecinde 21 katılımcı ile çalışılmış, test öncesi ve sonrası katılımcıların beyin aktiviteleri FMRI (Anlık Magnetik Rezonans Görüntüleme) yöntemi ile kaydedilmiştir. Eğitim büyük miktarda motor aktivitesi içermiştir. Tüm katılımcıların sağ elini kullandıkları tespit edilmiş ve bu yüzden sol el, kol ve bacaklarını daha koordine etmek zorunda kalmışlardır. Sonuç olarak; life kinetiğin içerdiği bilinmeyen denebilecek, alışılmışın dışında hareket ve görevlerin, kas-ko aktivasyon nedeniyle beyin bölgelerinin artan bağlanma gücü için ifade edilen beyin plastisitesini tetiklediğini bulmuşlardır (Demirakca vd., 2016).

Sportif branşlarda LK egzersiz kullanımına bakılacak olursa sıklıkla öğrenme, teknik ve taktik gelişime de katkı oluşturup oluşturulamayacağı üzerinde merak uyandırmaktadır. Karmaşık bir şekilde hareket ederken kişinin kendi bedeninin algısını harekete geçirir ve böylece kinetik ve vestibüler sistem eğitilir, bu da sporcuların özel bir hareket olmadığında bile belirli bilişsel prosedürleri kullanmalarını sağlar (Pietsch, Böttcher ve Jansen, 2017). Daha spesifik olarak, 
güreşçiler veya Cimnastikçiler gibi spor aktiviteleri sırasında görsel ve kinestetik süreçleri birbirine bağlamak zorunda kalan sporcular, koşu gibi başlıca kardiyovasküler spor aktiviteleri ile atletlerden daha iyi zihinsel rotasyon performans1 sergilemektedir (Moreau, 2012). Peker ve Taşkın (2016), life kinetiğin bilişsel işlemler üzerine etkisini araştırdığı çalışmasını 20 sağlıklı atlet üzerinde yapmıştır. Deney grubuna 12 hafta boyunca atletizm antrenmanlarının yanı sıra haftada üç gün $30 \mathrm{dk}$ life kinetik uygulamaları yapılmıştır. Deney grubunun planlama ve bilişsel işlem performansının kontrol grubuna göre istatistiksel açıdan daha yüksek olduğu bulunmuştur.

Takım sporları üzerine yapılan bir çalışmada Buraczewski, Cicirko ve Ciupińska (2016) Polonya Kadın Futbol Ligi'nde mücadele eden 18 futbolcuya Life Kinetik antrenmanların 12 hafta boyunca uygulamıştır. Yapılan testlerde ritim kullanılarak (dominant olan ve olmayan bacakla ses eşliğinde top sektirme) dominant olan ve olmayan ayak ile hedefe şut testleri yapılmıştır. Sonuçlar dominant olmayan bacakta anlamlı derecede gelişme olduğunu göstermiştir $(\mathrm{p}<0.05)$. Sonuç olarak araştırmacının tavsiyesi, life kinetiğin futbol oyuncularının antrenman programlarına dahil edilmesinin onların özel yeteneklerini geliştirmesine katkı sağlayacağı, böylece oyun performanslarının daha iyi olacağı yönünde olmuştur (Buraczewski, Cicirko ve Ciupińska, 2016). Bir başka çalı̧̧mada Vural (2016), life kinetiğin genç erkek basketbolcuların denge, dikkat ve reaksiyon süresi üzerindeki etkilerini incelemeyi amaçladığı çalı̧̧asında denekleri deney ve kontrol grubu olmak üzere ikiye ayırmıştır. Çalışma grubuna 12 hafta boyunca LK uygulamaları yaptırılmıştır. Çalışma grubunun işitsel ve görsel reaksiyon süreleri kontrol grubuna oranla anlamlı düzeyde daha kısa bulunurken $(p<0,05)$, denge skorlarında gruplar arasında istatistiksel anlamda fark bulunamamıştır.

\section{SONUÇ}

Yapılan araştırmalar incelendiğinde LK egzersizlerinin bilişsel süreci etkilediği açıkça görülmektedir. Bunun yanı sıra motor beceriler ve farklı fizyolojik parametreler üzerine etkileri olduğundan da araştırmalarda bahsedilmektedir. Sporcuların performans gelişimlerine katk1 sağlaması açısından değerlendirdiğimizde LK'in pozitif yönlü bir etki göstereceği söylenebilir. Hem alt yapı çalışmalarında teknik öğretiminin desteklenmesi hemde üst düzey sporcularda daha iyi bir performans sergilenmesi maksadiyla bu egzersiz modelinin antrenman programlarına dahil edilmesi olumlu katkılar sağlayabilir. Bu model ile rutin, yorucu ve tek düze devam eden antrenman programlarına eğlence katılabilir. Bunun yanısıra yeni, değişik, zorlayıcı ve hergün farklılaşan egzersizlerle sporcuların sadece performanslarını değil aynı zamanda antrenmanlara olan motivasyonları da artırlabilir.

\section{KAYNAKLAR}

Buraczewski, T., Cicirko, L. \& Ciupińska, A. (2016). The effectiveness of coordination training of female football players coordination abilities in physical education. In Coordination Abilities in Physcial Education, Sports and Rehabilitation (Ed., T. Niznikowski, J. Sadowski, W. Starosta), p. 43-55. Poland: International Association of Sport Kinetıcs Library Series.

Chib, S.S. (2000). Relationship of selected psychomotor variables and coordinativeabilities to playing ability in volleyball. (Yayımlanmamış doktora tezi). Lakshmibai National Institute of Physical Education Deemed Universty, India. 
Cotman, C.W., \& Berchtold, N.C. (2002). Exercise: A behavioral intervention to enhance brain health and plasticity. Trends in Neurosciences, 25(6), 295-301.

Demirakca, T., Cardinale, V., Dehn, S., Ruf, M., \& Ende, G. (2016). The exercising brain: changes in functional connectivity induced by an integrated multimodal cognitive and whole-body coordination training. Neural plasticity, 2016, 1-11. http://dx.doi.org/10.1155/2016/8240894.

Faigenbaum, A.D., Farrell, A., Fabiano, M., Radler, T., Naclerio, F., Ratamess, N.A., Kang, J. \& Myer, G.D. (2013). Effects of integrative neuromuscular training on fitness performance in children. Pediatr Exerc Sci, 23(4), 573-584.

FIFA 1904. (2019). Life kinetik, brain training for the pros. Erişim adresi: www.fifa.com.tr/magazine

Funk, M., Brugger P., \& Wilkening, F. (2014). Motor processes in children's imagery: the case of mental rotation of hands. Developmental Science, 8(5), 402-408.

Hyde, K., Lerch, J., Norton, A., Forgeard, M., Winner, E., Evans, A., \& Schlaug, G. (2009). The effects of musical training on structural brain development. Annals of the New York Academy of Sciences, 1169(1), 182186.

Jain, A., Bansal, R., Kumar, A. \& Singh, K.D.A. (2015). Comparative study of visual and auditory reaction times on the basis of gender and physical activity levels of medical first year students. Int J Appl Basic Med Res, 5(2), 124-127.

Life Kinetik. (2019). Life Kinetik. Erişim adresi: www.lifekinetik.com.tr/life-kinetik, 15 Haziran 2019.

Lutz, H. (2002). Life Kinetik, Gehirtraining durch Bewegung. Germany: Blv Buchverlag Gmbh\& Co.

Lutz, H. (2010). Fußball spielen mit LK. Münih: BLV.

Lutz, H. (2011). LK\&wetenschappelijk onderzoek research en samenstelling 1-8, Germany.

Lutz, H. (2014). Life Kinetik. Gehirntraining durch Bewegung, München, Germany: BLV.

Moreau, D. (2012). The role of motor processes in three-dimensional mental rotation: Shaping cognitive processing via sensorimotor experience. Learning and Indivual Differences, 22(2012), 354-359.

Nelson, C. A. (2000). The neurobiological bases of early intervention. In J. P. Shonkoff \& S. J. Meisels (Eds.), Handbook of early childhood intervention (pp. 204-227). New York, NY, US: Cambridge University Press.

Peker, A.T., ve Taşkın, H. (2016). The effect of LK trainings on coordinative abilities. 27 $7^{\text {th }}$ Proceedings of International Academic Conferences 5306946, 20 Oct., 2016. International Institute of Social and Economic Sciences. ISBN 978-80-87927-29-8.

Pietsch, S., Böttcher, C. \& Jansen, P. (2017). Cognitive motor coordination training improves mental rotation performance in primary school-aged children. Mind, Brain and Education, 11(4),176-180.

Vural, M.U. (2016). Life kinetik antrenmanının genç erkek basketbolcularda denge, reaksiyon süresi ve dikkat üzerine etkisi. (Yayımlanmamış yüksek lisans tezi). Gazi Üniversitesi Sağlık Bilimleri Enstitüsü Beden Eğitimi ve Spor Anabilim Dalı, Ankara.

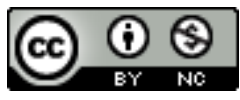

Bu eser Creative Commons Atıf-GayriTicari 4.0 Uluslararası Lisansı ile lisanslanmıştır. 